\title{
Repair of major congenital cardiac defects in low-birth-weight infants: Is delay warranted?
}

\author{
Charles W. Shepard, MD, ${ }^{\mathrm{a}}$ Lazaros K. Kochilas, MD, ${ }^{\mathrm{a}}$ Ronald M. Rosengart, MD, ${ }^{\mathrm{b}}$ Ann M. Brearley, PhD, MS, ${ }^{\mathrm{c}}$ \\ Roosevelt Bryant III, MD, ${ }^{\mathrm{d}}$ James H. Moller, MD, ${ }^{\mathrm{a}}$ and James D. St. Louis, MD ${ }^{\mathrm{d}}$
}

Objectives: Few studies have described the survival of low-birth-weight infants weighing less than $1.5 \mathrm{~kg}$ at operation for a cardiac malformation. Our goal was to determine if body weight at surgery affects survival.

\begin{abstract}
Methods: This was a retrospective cohort study using outcome data from the Pediatric Cardiac Care Consortium between 1982 and 2006.

Results: We reviewed the outcomes of 450 consecutive infants with a cardiac anomaly and a birth weight of less than $1.5 \mathrm{~kg}$, and weight of less than $2.5 \mathrm{~kg}$ at surgery. Of these, 179 patients had undergone surgery with a weight of less than $1.5 \mathrm{~kg}$ and 271 patients weighed 1.5 to $2.5 \mathrm{~kg}$ at surgery. The 30 -day survival rate was $83 \%$ for cohort 1 and $86 \%$ for cohort 2 . For patients not requiring cardiopulmonary bypass, the 30 -day survival rate was $86 \%$ for cohort 1 and $92 \%$ for cohort 2 . For patients requiring cardiopulmonary bypass, the 30-day survival rate was $69 \%$ for cohort 1 and $73 \%$ for cohort 2 . No notable improvement in the outcomes occurred over time.
\end{abstract}

Conclusions: For low-birth-weight infants (weight $<1.5 \mathrm{~kg}$ ) undergoing a major cardiac procedure, the survival of infants weighing less than $1.5 \mathrm{~kg}$ at surgery is comparable to that of infants who weighed 1.5 to $2.5 \mathrm{~kg}$. We conclude that, in our series, weight was not an independent risk factor for mortality, and, therefore, operative delay because of patient weight might be unwarranted. (J Thorac Cardiovasc Surg 2010;140:1104-9)

Earn CME credits at

http://cme.ctsnetjournals.org

During the past 5 decades, the care of children with cardiac lesions has progressed to the successful use of a wider range of cardiac operations. As the techniques have improved, a trend has occurred to operate on ever younger and smaller infants, with improving success. ${ }^{1}$ One persisting barrier relates to low-birth-weight infants $(<1500 \mathrm{~g})$ with an urgent need of operative repair or palliation.

Many studies have reviewed the safety and benefits of major cardiac surgery in infants weighing less than 2.5 kg. ${ }^{2-16}$ Very few of the infants included in these studies have weighed less than $1.5 \mathrm{~kg}$ at surgery, which raises the question, "How small is too small?" The decision to operate on such small infants is very difficult. Our

\footnotetext{
From the Departments of Pediatrics, ${ }^{\mathrm{a}}$ and Surgery, ${ }^{\mathrm{d}}$ and the Biostatistical Design and Analysis Center, Clinical and Translational Science Institute, ${ }^{\mathrm{c}}$ University of Minnesota, Minneapolis, Minn; and the Department of Pediatrics, ${ }^{\text {b }}$ Kaiser Permanente, Los Angeles, Calif.

Disclosures: None.

Read at the 90th Annual Meeting of The American Association for Thoracic Surgery, Toronto, Ontario, Canada, May 1-5, 2010.

Received for publication May 17, 2010; revisions received July 12, 2010; accepted for publication Aug 9, 2010; available ahead of print Sept 20, 2010.

Address for reprints: Charles W. Shepard, MD, Department of Pediatrics, University of Minnesota, 420 Delaware St SE, MMC 94, Minneapolis, MN 55455 (E-mail: shepa052@umn.edu).

0022-5223/\$36.00

Copyright (c) 2010 by The American Association for Thoracic Surgery

doi:10.1016/j.jtcvs.2010.08.013
}

retrospective multi-institutional study focused on infants with a birth weight of $1.5 \mathrm{~kg}$ or less to determine whether deferring cardiac surgery until the infant weighs more improves the chances of survival.

\section{MATERIALS AND METHODS}

A retrospective review of the data from the Pediatric Cardiac Care Consortium (PCCC), a multi-institutional database, from 1982 to 2006, revealed 105,609 infants and children with a cardiac anomaly who had undergone a cardiac operation from 58 participating centers. The institutional review board of the University of Minnesota approved the use of the database for research purposes. Because of the nature of the study, the patient or family consent requirement was waived. Infants who had undergone patent ductus arteriosus ligation as the primary operation were excluded from our analysis.

We reviewed the surgical outcomes of all low-birth-weight infants in the PCCC registry with a birth weight less than $1.5 \mathrm{~kg}$. Previous reports ${ }^{7,16}$ have suggested that infants with a weight of less than $2.5 \mathrm{~kg}$ at surgery have a particularly high risk of surgical mortality. We hypothesized that within this group, infants with a lower weight at surgery would be at the greatest risk, and we divided them into 2 subgroups: those weighing less than $1.5 \mathrm{~kg}$ at surgery, and those weighing 1.5 and $2.5 \mathrm{~kg}$ at surgery. The low-birth-weight infants who had undergone surgery weighing more were most likely to be hemodynamically stable and growing and therefore were not included in the present analysis. We reviewed the cardiac diagnosis, operation types, and survival outcomes. The patient survival rates were evaluated for both 30-day and in-hospital survival (survival until discharge, if $>30$ days). The effects of the year of surgery and weight class on survival were investigated using contingency table methods and Fisher's exact tests. All data analysis was performed using the Statistical Analysis Systems, version 9.2 (SAS Institute, Inc, Chicago, Ill).

\section{RESULTS}

Using these entry criteria, we identified 450 infants from 47 participating centers with a birth weight of 320 to $1500 \mathrm{~g}$. 


\section{Abbreviations and Acronyms \\ $\mathrm{CPB}=$ cardiopulmonary bypass \\ $\mathrm{PCCC}=$ Pediatric Cardiac Care Consortium}

Of these 450 infants, 179 had undergone surgery at a weight of less than $1500 \mathrm{~g}$ and 271 at a weight of 1.5 to $2.5 \mathrm{~kg}$. The infants studied had a variety of cardiac conditions commonly requiring surgery in the neonatal period (Table 1). The types of operations performed were similar between the 2 groups (Table 1). The age at surgery ranged from 0 to 139 days (mean 21 days, median 14 days, mode 13 days) for those weighing less than $1500 \mathrm{~g}$. The age at surgery ranged from 5 to 153 days (mean 58 days, median 53 days, mode 49 days) for the group weighing 1.5 to 2.5 $\mathrm{kg}$. The risk assessment for congenital heart surgery score (RACHS) was recorded for each group. The range was 1 to 6 , with a mean of 2.65 for the group weighing less than $1.5 \mathrm{~kg}$ and a mean of 2.56 for the heavier group (Figure 1).

A total of 179 infants underwent cardiac surgery at a weight of less than $1.5 \mathrm{~kg}$. The 30-day survival rate for that group was $83 \%(\mathrm{n}=148)$. The in-hospital survival rate was $73 \%(\mathrm{n}=130)$. A total of 271 infants underwent cardiac surgery at a weight of 1.5 to $2.5 \mathrm{~kg}$. The 30 -day survival rate was $86 \%(n=233)$. The in hospital survival rate was $77 \%$ (Figure 2). A statistical analysis of survival as a function of weight class was performed using Fisher's exact $\chi^{2}$ test and yielded a $P$ value of .352 for the 30-day survival and $P=.263$ for in-hospital survival. The survival rates were not different between the infants undergoing surgery weighing less than $1.5 \mathrm{~kg}$ and those undergoing surgery weighing 1.5 to $2.5 \mathrm{~kg}$.

We analyzed the operative outcomes of these 2 groups by 5 -year periods (Figure 3). Surgery was performed on more low-weight infants each year during the study; however, more hospitals were also participating in the PCCC with time. The statistical analyses of survival as a function of period, both ignoring the weight class and considering the weight class, were performed using Fisher's exact tests. All $P$ values were $>$.4. Thus, no statistically significant improvement in outcome occurred over time.

Finally, survival after various types of operations was assessed. Infants in whom more than 1 procedure was performed at the same operation were classified according to the procedure with the greatest risk assessment for congenital heart surgery score. The patients were divided according to 3 types of procedures: (1) not requiring cardiopulmonary bypass $(\mathrm{CPB})$; (2) operations needing $\mathrm{CPB}$; and (3) pacemaker implantation. The 30-day survival rates for each category are listed in Table 1 and shown in Figure 4, stratified by weight group. Because at least 5 comparisons were made within each of the operative categories, the
Fisher's exact test $P$ values were compared to a Bonferroni-adjusted $\alpha$ value of 0.01 .

Of the operations performed without $\mathrm{CPB}$, the only subgroup that showed a trend toward a statistically significant improvement in the group weighing more for 30-day survival was the coarctation of the aorta repair group $(P=.03)$. When evaluating all those undergoing operations not needing $\mathrm{CPB}$, no improvement was seen in the survival of the higher weight group versus the lower weight group $(P=.14)$ (Table 1 and Figure 4).

For operations in which CPB was used, the survival in the heavier group of neonates was no different from those in the lower weight group $(P=.67)$.

Finally, 11 infants weighing less than $1.5 \mathrm{~kg}$ and 6 infants weighing 1.5 to $2.5 \mathrm{~kg}$ at surgery underwent pacemaker implantation for heart block. In the group weighing less than $1.5 \mathrm{~kg}, 7$ infants survived to 30 days $(64 \%)$, and in the heavier group, 5 survived to 30 days $(83 \%)$. No statistically significant difference was seen in survival for the heavier group compared with the lower weight group $(P=.60)$.

No deaths occurred in the less than 1.5-kg group (unless coupled with another procedure) for the following procedures: vascular ring surgery $(\mathrm{n}=8)$, cardiac tumor surgery $(\mathrm{n}=1)$, truncus arteriosus repair $(\mathrm{n}=1)$, ventricular septal defect repair $(n=2)$, complete atrioventricular canal repair $(\mathrm{n}=1)$, and ligation of an anomalous coronary artery $(\mathrm{n}=1)$.

\section{DISCUSSION}

It is difficult to balance the appropriate care of a premature or low-birth-weight infant with a major cardiac lesion. Infants with a cardiac anomaly are at an increased risk of birth weight. ${ }^{17}$ Furthermore, very-low-birth-weight neonates with a cardiac anomaly have increased overall mortality compared with heavier and more mature infants. ${ }^{13}$ Such neonates often have extracardiac malformations ${ }^{4}$ and other issues related to prematurity. ${ }^{18}$ When combined with an unrepaired cardiac malformation, severe and prolonged morbidity can result. ${ }^{4,19}$ The timing of the operation is important, because undue delay can worsen the neonate's condition without the benefit of improved cardiovascular status. ${ }^{2,19}$ Chang and colleagues ${ }^{2}$ showed that delayed intervention increased morbidity and mortality, without additional benefit. Reddy and colleagues ${ }^{5}$ found that delayed intervention was associated with increased complications, such as ventilator dependency, poor weight gain, sepsis, necrotizing enterocolitis, chronic pulmonary disease, and renal failure, especially in very-low-weight infants. They concluded that corrective (instead of palliative) surgery should be considered, even in the very-low-weight groups, when technically feasible. ${ }^{4-6,14}$

In 2000, Reddy and Hanley ${ }^{4}$ reported that a delay in repair results in "extraordinary morbidity" and that more 
TABLE 1. Patient characteristics and 30-day survival stratified by weight group and operation type

\begin{tabular}{|c|c|c|c|}
\hline Variable & Surgical weight $<1.5 \mathrm{~kg}$ & Surgical weight $1.5-2.5 \mathrm{~kg}$ & $P$ value \\
\hline Total infants & 179 & 271 & \\
\hline Birth weight (kg) & $1.04(0.46-1.48)$ & $1.18(0.32-1.50)$ & $.197 *$ \\
\hline Surgical age (d) & $21(0-139)$ & $58(5-153)$ & $.0001^{*}$ \\
\hline RACHS-1 score & $2.65(1-6)$ & $2.56(1-6)$ & $.717 *$ \\
\hline \multicolumn{4}{|l|}{ Operations with CPB } \\
\hline Type & Survived/total (\%) & Survived/total (\%) & \\
\hline VSD/AV canal repair & $10 / 11(91 \%)$ & $26 / 29(90 \%)$ & 1 \\
\hline ASD repair & $2 / 2(100 \%)$ & $7 / 7(100 \%)$ & 1 \\
\hline RVOT repair & $5 / 8(63 \%)$ & $6 / 13(46 \%)$ & .66 \\
\hline HLHS repair & $1 / 7(14 \%)$ & $6 / 9(67 \%)$ & .06 \\
\hline TAPVR repair & $1 / 2(50 \%)$ & $7 / 9(78 \%)$ & .49 \\
\hline Other & $8 / 9(89 \%)$ & $11 / 19(58 \%)$ & .20 \\
\hline All operations with CPB & $27 / 39(69 \%)$ & $63 / 86(73 \%)$ & .67 \\
\hline \multicolumn{4}{|l|}{ Operations without CPB } \\
\hline \multicolumn{4}{|l|}{ Type } \\
\hline Coarctation/arch repair & $64 / 72(89 \%)$ & $69 / 70(99 \%)$ & .03 \\
\hline Shunts & $21 / 27(78 \%)$ & $67 / 75(89 \%)$ & .19 \\
\hline Pulmonary artery banding & $21 / 22(95 \%)$ & $25 / 29(86 \%)$ & .37 \\
\hline Vascular ring repair & $8 / 8(100 \%)$ & $4 / 4(100 \%)$ & 1 \\
\hline Pacemaker placement & $7 / 11(64 \%)$ & $5 / 6(83 \%)$ & .60 \\
\hline RV perforation repair & $0 / 0$ & $0 / 1$ & NA \\
\hline All operations without CPB & $121 / 140(86 \%)$ & $170 / 185(92 \%)$ & .14 \\
\hline All operations & $148 / 179(83 \%)$ & $233 / 271(86 \%)$ & .35 \\
\hline
\end{tabular}

$P$ values from Fisher's exact tests. Because of multiple comparisons, none reached statistical significance. RVOT group included transannular patch repair (4 and 9), infundibular resection ( 1 and 2), and pulmonary valvectomy ( 3 and 2 patients, respectively). RACHS-1, risk adjustment for congenital heart surgery; $C P B$, cardiopulmonary bypass; VSD, ventricular septal defect; $A V$ canal, atrioventricular canal defect; $A S D$, atrial septal defect; $R V O T$, right ventricular outflow tract; HLHS, hypoplastic left heart syndrome; TAPVR, total anomalous pulmonary venous return; $R V$, right ventricular. *Performed using JMP software (SAS Institute).

favorable results were achieved with early repair in verylow-weight infants $(<1500 \mathrm{~g})$. None of their patients had intracranial bleeding, even when $\mathrm{CPB}$ was required. They had success with, and suggested early and complete repair of, simple and even highly complex cardiac anomalies in this group of small infants. They also found that the complication rates and need for reintervention was similar

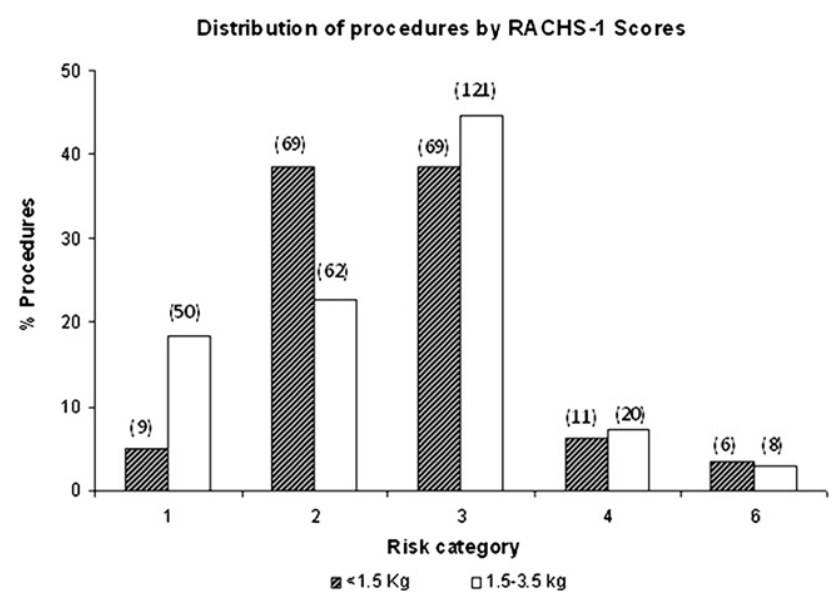

FIGURE 1. Risk assessment for congenital heart surgery scores had similar distribution in both groups, with mean score of 2.65 for less than $1.5-\mathrm{kg}$ group and 2.55 for $1.5-$ to $2.5-\mathrm{kg}$ group. to those of full-term neonates. This challenging subgroup of neonates might be best treated at centers with expertise in caring for very-low-weight neonates, especially if symptomatic or ventilator dependent. ${ }^{4,5}$

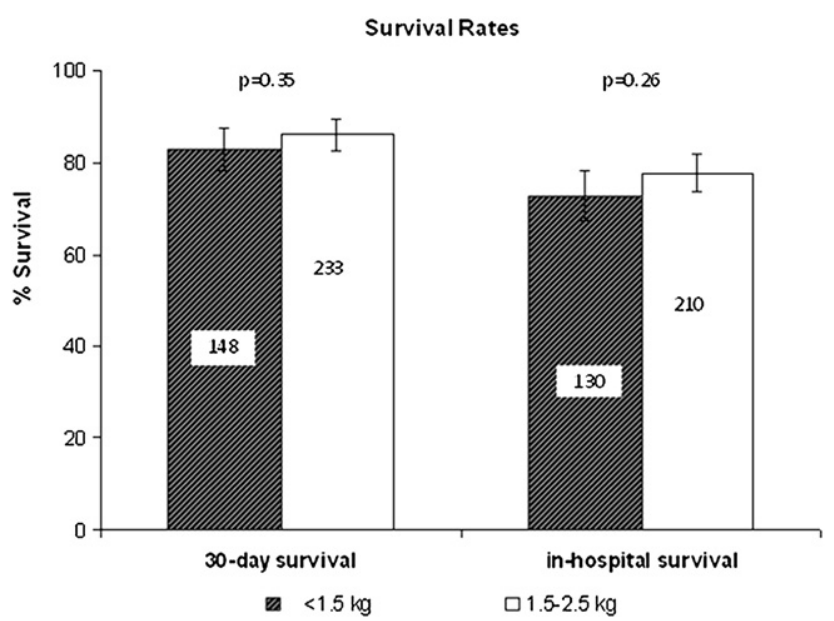

FIGURE 2. Rates of 30-day and in-hospital survival by weight group, with 179 infants in the less than $1.5-\mathrm{kg}$ group and 271 infants in the $1.5-$ to $2.5-\mathrm{kg}$ group. Error bars indicate $95 \%$ confidence intervals for survival proportions. Fisher's exact tests gave no evidence of differences in 30-day survival ( $P=.3522)$ or in-hospital survival $(P=.2630)$ between the weight groups. 


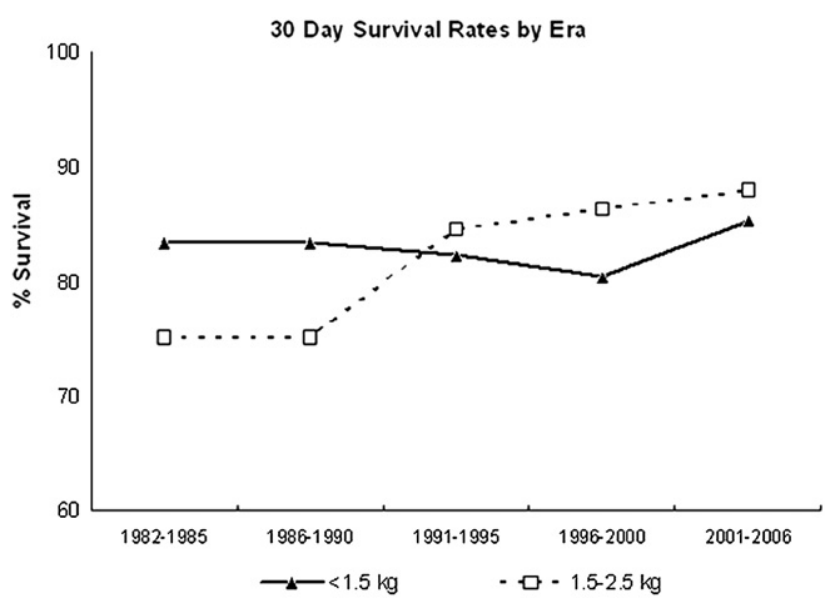

FIGURE 3. Rates of 30-day survival by era for the 2 weight groups. Fisher's exact tests gave no evidence of a time trend in 30-day survival $(P>.5)$. Increasing number of patients undergoing surgery over time might have resulted from increased number of programs participating in Pediatric Cardiac Care Consortium (PCCC) database over time.

One study noted that very-low-birth-weight neonates, in general, have a high incidence of neurologic handicaps. The immature blood-brain barrier has increased permeability, a greater potential for brain edema, and a greater incidence of spontaneous intracerebral/intraventricular bleeding. The investigators suggested that $\mathrm{CPB}$ might increase this risk but described only 2 such cases. ${ }^{15}$

A recent study by Curzon and colleagues ${ }^{16}$ compared the outcomes of infants weighing 1.5 to $2.5 \mathrm{~kg}$ with those of patients weighing 2.5 to $4 \mathrm{~kg}$ at surgery, without regard to the birth weight. They found that certain subgroups in the lower weight population had elevated mortality rates compared with their heavier counterparts, including coarctation of

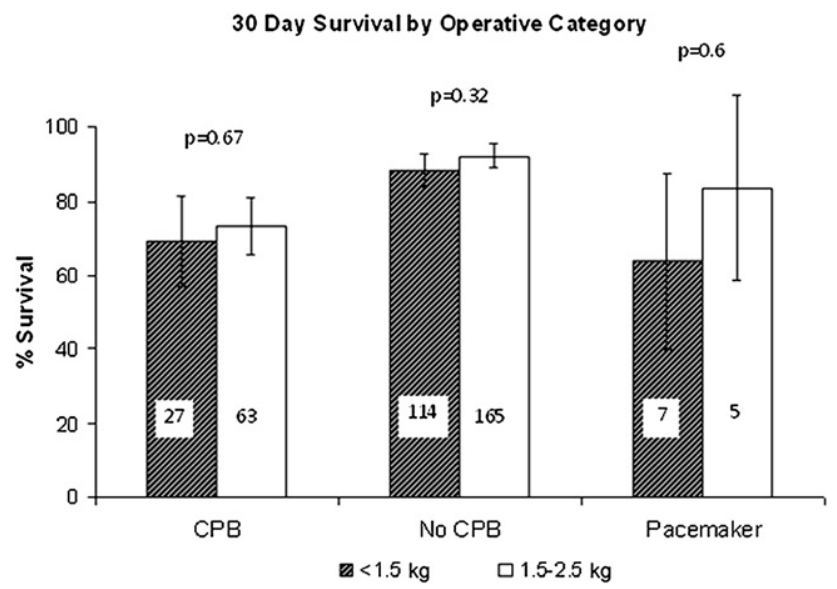

FIGURE 4. Rates of 30-day survival by operative category for the 2 weight groups. (Operations involving a pacemaker were separated from the "no CPB" group for Figure 4.) Error bars indicate $95 \%$ confidence intervals for survival proportions. Fisher's exact tests gave no evidence of difference in 30-day survival between the 2 weight groups for any of the 3 operative categories $(P>.14)$. the aorta, total anomalous pulmonary venous connection, d-transposition of the great arteries, pulmonary atresia with a ventricular septal defect, and single ventricle lesions. The overall survival rate of the less than $2.5-\mathrm{kg}$ group was $84 \% .{ }^{16}$ Our population was not large enough to statistically evaluate such subdivisions.

The perioperative risk factors must also be considered. Several risk-stratifying categories exist (eg, risk assessment for congenital heart surgery score and Aristotle ${ }^{20,21}$ ) to help clinicians assess the postoperative prognosis. Preoperative acidosis and the need for inotropic support are significant risk factors for a poor outcome. ${ }^{14}$ A prolonged crossclamp time, extracorporeal membrane oxygenation, palliative (instead of corrective) surgery, prolonged intensive care unit stay, and prolonged ventilator dependency have each been associated with worse outcomes. ${ }^{14}$

Our study had some important limitations related to the nature of the PCCC database. For example, the registry does not include information about the perioperative status (ie, gestational age, complications, central nervous system events) or the clinical indications for proceeding with or delaying surgery. Some patients who survived an initial operation did not survive a subsequent one. The available data did not allow quantification of long-term survival. A limited number of high complexity cases were included in the CPB group, with only a few in each specific operation. Therefore, the conclusions of our study do not necessarily extrapolate to this unique population. Finally, another important limitation was that infants with cardiac defects who do not undergo an intervention are not reported to the database.

For the 25 years for which we have data, an increasing number of low-birth-weight infants underwent surgery at these centers. For low-birth-weight infants undergoing surgery for cardiac lesions, we found no supportive evidence that surgery at a weight of 1.5 to $2.5 \mathrm{~kg}$ improved the survival rate compared with surgery at a weight of less than $1.5 \mathrm{~kg}$. In our series, the survival rate for low-birth-weight infants remained relatively constant from 1982 to 2006 for either weight class.

The 1.5- to $2.5-\mathrm{kg}$ group underwent surgery an average of 37 days later than the less than $1.5-\mathrm{kg}$ group. The mortality rates were not significantly different, except for a borderline significant difference for infants undergoing coarctation repair $(P=.03)$. When those undergoing $C P B$ were subdivided by procedure, few patients were in each of the high complexity groups. Of these patients, those with hypoplastic left heart syndrome and a greater weight had borderline significantly improved survival $(P=.06)$; however, larger numbers are required to confirm this finding. In the other groups, no evidence was found of a benefit from delaying surgery for infants with a birth weight less than 1.5. Furthermore, delaying surgery causes the neonates to be exposed to prolonged intensive care (including mechanical ventilation, inotropic support, prostaglandin exposure, the potential for 
infection, and so forth) and its complications while having poor weight gain. On the other hand, if the infant could avoid these exposures, the data suggest that waiting might not be detrimental. As expected, CPB resulted in greater risk than procedures that did not require its use; however, the outcomes were similar for both weight groups. Our findings approximate the success rates found in previous studies. ${ }^{13,14}$ Previous studies ${ }^{2-15}$ have reported the singlecenter experience from highly specialized centers. These reports typically included only limited numbers of patients in the very-low-weight group, because this is such a unique population. In contrast, our study has provided the accumulated experience of many small and mid-size centers across the United States and Canada. Thus, the information from our study is unique and helpful as more cardiac centers consider early cardiac repair for low-weight neonates. The morbidity and long-term outcomes should be studied further as more infants in this population undergo early corrective surgery.

Cardiologists, surgeons, and neonatologists must collaborate to prepare the patient for surgery and should not use weight as the sole factor for operative timing, because these infants will have poor weight gain until the correction is performed. ${ }^{18}$ The techniques and skill levels are continuously improving, making it ever safer to correct complex cardiac malformations. Knowing the likelihood of success can help the decision of when to operate and affords families realistic expectations of the final outcome.

\section{References}

1. Boneva RS, Botto LD, Moore CA, Yang Q, Correa A, Erickson JD. Mortality associated with congenital heart defects in the United States: Trends and racial disparities, 1979-1997. Circulation. 2001;103:2376-81.

2. Chang AC, Hanley FL, Lock JE, Castaneda AR, Wessel DL. Management and outcome of low birth weight neonates with congenital heart disease. J Pediatr. 1994;124:461-6.

3. Beyens T, Biarent D, Bouton JM, Demanet H, Viart P, et al. Cardiac surgery with extracorporeal circulation in 23 infants weighing $2500 \mathrm{~g}$ or less: Short and intermediate term outcome. Eur J Cardiothorac Surg. 1998;14:165-72.

4. Reddy VM, Hanley FL. Cardiac surgery in infants with very low birth weight. Semin Pediatr Surg. 2000;9:91-5.

5. Reddy VM, McElhinney DB, Sagrado T, Parry AJ, Teitel DF, et al. Results of 102 cases of complete repair of congenital heart defects in patients weighing 700 to 2500 grams. J Thorac Cardiovasc Surg. 1999;117:324-31.

6. Pawade A, Waterson K, Laussen P, Karl TR, Mee RB. Cardio-pulmonary bypass in neonates weighing less than $2.5 \mathrm{~kg}$ : Analysis of the risk factors for early and late mortality. J Cardiac Surg. 1993;8:1-8.

7. Oppido G, Napoleone CP, Formigari R, Gabbieri D, Pacini D, et al. Outcome of cardiac surgery in low weight and premature infants. Eur J Cardiothorac Surg. 2004;26:44-53.

8. Dees E, Lin H, Cotton RB, Graham TP, Dodd DA. Outcome of preterm infants with congenital heart disease. J Pediatr. 2000;137:653-9.

9. Pizarro C, Davis DA, Galantowicz ME, Munro H, Gidding SS, Norwood WI. Stage I palliation for hypoplastic left heart syndrome in low birth weight neonates: Can we justify it? Eur J Cardiothorac Surg. 2002;21:716-20.

10. Kawata H, Kishimoto H, Miura T, Nakajima T, Kitajima H. Surgical management of congenital cardiac defects in neonates and young infants born with extremely low weight. Cardiol Young. 2003;13:328-32.

11. Rossi AF, Seiden HS, Sadeghi AM, Nguyen KH, Quintana CS, et al. The outcome of cardiac operations in infants weighing two kilograms or less. J Thorac Cardiovasc Surg. 1998;116:28-35.
12. Levin DL, Stanger P, Kitterman JA, Heymann MA. Congenital heart disease in low birth weight infants. Circulation. 1975;52:500-3.

13. Kecskes Z, Cartwright DW. Poor outcome of very low birth-weight babies with serious congenital heart disease. Arch Dis Child Fetal Neonatal Ed. 2002;87: F31-3.

14. Netz BC, Hoffmeier A, Krasemann T, Zahn P, Scheld HH. Low weight in congenital heart surgery: Is it the right way? Thorac Cardiovasc Surg. 2005;53: 330-3.

15. Borowski A, Schickendantz S, Mennicken U, Korb H. Open heart interventions in premature low- and very-low-birth-weight neonates: Risk profile and ethical considerations. Thorac Cardiovas Surg. 1997;45:238-41.

16. Curzon CL, Milford-Beland S, Li JS, O'Brien SM, Jacobs JP, et al. Cardiac surgery in infants with low birth weight is associated with increased mortality: Analysis of the Society of Thoracic Surgeons Congenital Heart Database. J Thorac Cardiovasc Surg. 2008;135:546-51.

17. Kramer HH, Trampisch HJ, Rammos S, Giese A. Birth weight of children with congenital heart disease. Eur J Pediatr. 1990;149:752-7.

18. Wernovsky G, Rubenstein SD, Spray TL. Cardiac surgery in the low-birth-weight neonate: New approaches. Clin Perinatol. 2001;28:249-64.

19. Marino BS, Bird GL, Wernovsky G. Diagnosis and management of the newborn with suspected congenital heart disease. Clin Perinatol. 2001;28:91-136.

20. Jenkins KJ, Gauvreau K, Newbuger JW, Spray TL, Moller JH, et al. Risk adjustment for congenital heart surgery: The RACHS-1 method. Semin Thorac Cardiovasc Surg Pediatr Card Surg Ann. 2004;7:180-4.

21. Lacour-Gayet F, Clarke D, Jacobs J, Comas J, Daebritz S, et al. The Aristotle score: A complexity-adjusted method to evaluate surgical results. Eur J Cardiothorac Surg. 2004;25:911-24.

\section{Discussion}

Dr Peter J. Gruber (Philadelphia, Pa). Dr Shepard, thank you for your very clear presentation on this difficult set of patients and, especially, your willingness to review over 105,000 charts.

We are frequently faced with decisions as to when to operate on small infants, and, when we need to do so, we must decide on the best operative strategy, whether palliation or complete repair, as well as the timing. Certainly, in the past 10 years there has not been much hesitancy on the part of most surgeons to perform complex operations, regardless of weight, for purely technical reasons. Indeed, as you point out in your presentation, there has been substantial data reporting the safety and benefits of expeditious surgery, even in small infants. However, there is also, as you point out, considerable evidence that complications increase with lower body weight. The most prominent among these is the comprehensive analysis of the Society of Thoracic Surgeons database reported 2 years ago by Dr Curzon that compared the mortality in patients weighing less than and more than $2.5 \mathrm{~kg}$ for several operative procedures. The results of that study comprehensively documented an increase in mortality for the group weighing less than $2.5 \mathrm{~kg}$ for many operative groups.

You asked a different question using a different approach and divided that highest risk group into 2 categories, those less than $1.5 \mathrm{~kg}$ and those greater than $1.5 \mathrm{~kg}$ but less than $2.5 \mathrm{~kg}$, and to my knowledge, the precise analysis of this group has not previously been reported.

To me, the results were a little surprising. One might have expected that those less than $1.5 \mathrm{~kg}$ would have had worse outcomes than those greater than $1.5 \mathrm{~kg}$, and, in general, you showed that they did not.

So I have 3 questions for you.

The first is on the elaboration of the Pediatric Cardiac Care Consortium (PCCC) and its relationship to the Society of Thoracic Surgeons database and whether any of these patients overlap- 
450 infants from almost 50 centers within 25 years is about 1 per center every 2 years, which is a highly heterogeneous group.

Dr Shepard. First, regarding the PCCC, this is a database that was started in 1982 at the University of Minnesota that through the years has grown. Programs have added themselves and other taken themselves out of this database throughout those years. There is overlap with the Society of Thoracic Surgeons database (some centers participate in both databases), and so some of these patients might have also been in that database. As to the second part of the question, we considered the participation over time for these centers. It was not as heterogeneous as 1 patient every other year per institution. There were institutions that during the 25-year period entered as few as 1 patient, and I believe the most patients from any given institution was about 11 . This is such a small specialized population that it is very hard to find large numbers for this group.

Dr Gruber. The second question, I would be curious to know whether you noted historical differences in patients operated on during almost a quarter of a century. There has been considerable refinement in the techniques both intra- and perioperatively. Did you see any improvement over that time?

Dr Shepard. We know from previous studies that in heavier weight infants and children, there was an improvement in surgical outcomes over time. In our study, we evaluated by 5 -year periods and found no improvement over time for this low-weight population, looking at all institutions. There might have been more of an effect if we had isolated just the larger institutions and looked at their improvement curves over time; however, that was not part of this study.

Dr Gruber. My last question is regarding gestational age. Were these patients small for gestational age and/or premature? Certainly, there is a close relationship between prematurity and small for gestational age, but they might underscore different mechanisms of risk. Can you comment?

Dr Shepard. That is a very important point, and one that I would very much like to look into further. That information was not included uniformly in our database so that would need to be a case-by-case review. However, I believe that would add more light to this subject, as would other questions of preoperative variables that added in and led to the timing of these procedures that were unclear from the data that we have in our database.

Dr Harald L. Lindberg (Oslo, Norway). I have no disclosures. Congratulations on a very nice paper.

But I wonder, were there any deaths in the group that was waiting for surgery? Do you have any information on that at all? Because that would be a really major influence on your results if you have a certain percentage of death or morbidity from waiting for surgery, that would advocate earlier repair.

Dr Shepard. This database records the cardiac operations and catheterizations so those patients who do not make it to surgery or cardiac catheterization will not be in the database. That would be a wonderful addition to this study if I could find that information.

Dr Lindberg. A second question, do you have any information if there were more patients on the ventilator or inotropic support in the group that waited for surgery or those who were primarily operated?

Dr Shepard. These preoperative co-factors would help us to understand why some patients were operated on early versus late and might offer further insight into the question of surgical timing in these high-risk infants. The PCCC does not record that information, so it would have to come from a chart-by-chart review, with charts from 47 different centers.

Dr Ali Dodge-Khatami (Hamburg, Germany). Among these patients there were a lot of shunts, coarctations, and also pulmonary artery bandings. For those of us in the room who are perhaps less bold to undertake such surgery in these very small infants, I did not get what percentage of these cases were done electively or what percentage were done because you had no other choice, with your back to the wall, let us say, extreme cyanosis or, on the other hand, cardiac failure?

The corollary to that question would be, if you do have the choice of waiting a bit longer to perhaps let the infants grow a bit more-of course, 38 more days in the hospital is a long time with cost issues, et cetera-but would it be justified to wait in some of these patients if you can? Do you have that percentage?

Dr Shepard. I do not have that percentage or that information. We did not have, again, the reason for timing of the intervention of the operation. That is something that would be very beneficial to add on as a follow-up to this study to determine why the timing was such and whether there would be an advantage to waiting or a reason for going early.

Dr Glen Van Arsdell (Toronto, Ontario, Canada). That was a nice presentation and you have done a nice job explaining the limitations of the paper because you did not have the ability to enroll based on an intention to treat.

One of the questions I have is how did you choose the weight for creating the 2 groups? Some studies have taken the approach of saying let us look at risk on an incremental weight basis. Did you analyze weight as a continuous variable as opposed to a categorical variable?

Dr Charles Shepard. We did not analyze weight as a continuous variable. We chose $1.5 \mathrm{~kg}$ as the marker that had been set in the past as a very high-risk category. Then, in an attempt to have a comparison group, we chose those that were at a heavier operative weight but similar birth weights and similar risk assessment for congenital heart surgery scores.

Dr Van Arsdell. It might be an interesting analysis to do, because a number of studies have shown that weight, as an incremental component, is a risk of poor outcomes. 